\title{
Investigation of type and density of bio-aerosols in air samples from educational hospital wards of Kerman city, 2014
}

\author{
Mohammad Malakootian $^{1,2^{*}}$, Majid Amiri Gharghani ${ }^{3}$ \\ ${ }^{1}$ Professor, Environmental Health Engineering Research Center, Kerman University of Medical Sciences, Kerman, Iran \\ ${ }^{2}$ Professor, Department of Environmental Health, School of Public Health, Kerman University of Medical Sciences, Kerman, Iran \\ ${ }^{3} \mathrm{MSc}$ Student of Environmental Health Engineering, Department of Environmental Health, School of Public Health, Kerman University \\ of Medical Sciences, Kerman, Iran
}

\begin{abstract}
Background: Bio-aerosols in the air of hospital wards have an important role in the development of infections. It is important to make quantitative and qualitative estimations of microorganisms in the air of these wards as an index for environmental hygiene applicable to different hospital wards. The aim of the study was to investigate degrees of diversity and density of bio-aerosols in the education hospitals of Kerman city.

Methods: This study applied a descriptive-cross-sectional methodology in the second half of 2014 in the education hospitals of Kerman city, with bed capacity of over 300. As many as 200 samples were collected from the air in different wards of each hospital using the standard method of the National Occupational Health and Safety Institute. Following collection, samples were placed in an incubator for 48 hours and then bio-aerosol detections were made for and resulting data reported as colonies $/ \mathrm{m}^{3}$. Results: Results indicated that maximum and minimum degrees of bacterial density were observed in operation rooms and in the intensive care unit (ICU) of Shafa hospital. Furthermore, comparison showed that the operating room at Afzalipour hospital had the lowest level of fungal contamination, while ICU at Bahonar hospital had the highest level of fungal contamination. The emitted fungi of Aspergillus and Penicillium along with the bacteria, staphylococci and Acinetobacter had greater frequencies. The means of bacterial density and fungal density were not equal across the studied hospitals and significant statistical, difference was observed between means of bacterial and fungal density $(P \leq 0.001)$.

Conclusion: Amounts of bacterial and fungal density were greater than those proposed in the American Industrial Health State Conference in $73.3 \%$ of the wards in the educational hospitals of Kerman city sampled in this study. Therefore it is suggested that implementation of some, necessary measures for continuous monitoring, promotion of hygienic disinfection standards, and ventilation systems are taken more seriously by stipulating regulations to control this important issue in the country's hospitals. Keywords: Bacteria, Fungal, Bio-aerosol, Hospital, Kerman

Citation: Malakootian M, Amiri Gharghani M. Investigation of type and density of bio-aerosols in air samples from educational hospital wards of Kerman City, 2014. Environmental Health Engineering and Management Journal 2016; 3(4): 197-202. doi: 10.15171/EHEM.2016.20.
\end{abstract}

\section{Article History:}

Received: 2 August 2016

Accepted: 17 September 2016

ePublished: 1 October 2016

\section{Introduction}

Public health has always been influenced by physical, chemical, and biological factors of the ambient air. The air of closed spaces, given that they often contain different types of bio-aerosol, has great potential for jeopardizing the health of patients (1). Therefore, supervision of the quality of air inside buildings is crucial, especially in places where health care is administered (2).

The World Health Organization (WHO) considers hospitals as an integral part of the social environment as they have a major role in provision of healthcare in a society (3). A hospital is a place where employees, patients, visitors, and in some cases students are in contact with microorganisms that could jeopardize their health (4). If health and protective issues are neglected in such places then incidence of infections may be encouraged (5). Based on studies, the most common hospital infections in decreasing order have been reported as; urinary tract infections, infections of surgical scars, pneumonia, bacteremia, and septicemia (5-8). As hospital infections increase dangers of microbial contamination and cause mortality in developed and developing countries, 5\%-10\% in developed and over $25 \%$ in developing countries, it is crucial that the problem is given greater attention (9). Studies show a significant relationship between level of hospital infection and level of bio-aerosols in the air. Generally, the solid or liquid particles in the air of hospitals contain different types of bacterial, viral and fungal pathogens $(5,8)$. The major pathogens to cause hospital infections include Aspergillus flavus, gram-positive bacilli, 
Neisseria meningitidis, Serratia marcescens, Staphylococcus aureus, Streptococcus pyogenes, and bacillus tuberculosis and they cause pathogenesis from hospital air through transmission from skin, exhaled air, operation room transmission, surgical instruments, contaminated clothes of patients $(10,11)$. Parts of the body that are more prone to hospital infections include aggressive systems such as counters, discharge operations, and patients who have a compromised immune system (9-12).

Supervision on biological bio-aerosol in hospitals can provide information for epidemiological investigation of hospital infections, research on microorganisms present in the air, development and qualitative control, as well as information about their current status (13). Quantitative and qualitative estimations of levels of microorganisms in the air reveal its value as an index for environmental hygiene and as an index related to human health (14). Omoigberale et al reported a study on hospital bio-aerosols in 2 hospitals in Nigeria. It reports the greatest microbial density in the waiting room, and the lowest density in the surgical operation room. Furthermore, 6 bacterial and 6 fungal species were detected (9). Choobineh et al reported a study on the type and density of bio-aerosols in Shiraz hospitals that determined higher-than-standard levels of contamination (4). Gioffre et al reported on a study on airborne microorganisms in operation rooms. Around 10\% of hospital infections in hospitalized patients without any underlying disease were caused by organisms transmitted through air (15). Moreover, the degree of emission of bioaerosols in the air surrounding Kerman city wastewater treatment plant was examined by Malakootian et al (16). As hospital infection caused problems such as prolongation of hospitalization time, development of disease, decreased productivity in a working environment as well as staff absence; such problems placed a heavy cost burden to health systems in developing countries (17). Considering that prevention and control are better than treatment, and regarding the direct relationship between hospital infection and the level of hospital contamination, the necessity of evaluating and detecting microbial contamination and demolition of contaminating sources needs more emphasis. Thus this study was performed with the aim of investigating the diversity and density of bio-aerosols in the educational hospitals of Kerman city, with a capacity of over 300 beds, in 2014 .

\section{Methods}

Thestudyapplied descriptive-cross-sectional methodology with sampling taken for a period of 6 months in the second half of 2014 in three public hospitals: Afzalipour, Shafa, and Bahonar in Kerman, with a bed capacity of 300 . Five wards were selected from each hospital considering texture, significance of the type of hospital, and according to suggestions made by the infection control committee. The culture medium used for growing bacteria was blood agar, while Sabro Dextrose Agar (SDA) was used for fungal growth (18). A total of 198 samples were collected from the three hospitals; 95 and 103 samples were used for bacterial and fungal growth, respectively. To remove interfering factors and human error, one control sample was adopted from each site and the samples were taken twice: once in the morning and once in the afternoon. Sampling was taken in the operating room immediately after an operation and in other wards at 8-12 AM and 1416 PM. Sampling taken by the active method based on the standard method 0800 of the National Institute of Occupational Safety \& Health (NIOSH). Here, the particle collision method into plates containing culture medium using a single-stage Anderson impactor (separator of particles by collision method) and ZEFON pump attached to a rotameter (Taiwan) with a flow rate of $26.7 \mathrm{~L} / \mathrm{min}$. Sampling time was 12 minutes for each plate containing a culture medium already prepared under standard and sterilized conditions for the specified stations.

Before the start of sampling, the rotameter was calibrated and at each time of sampling, the placement site of the culture medium was fully disinfected using alcohol and only used after it had dried. For sampling, the sampler device was placed at $1.20 \mathrm{~m}$ above ground level at a distance of over $1 \mathrm{~m}$ from walls and obstructions (19). The plates containing the culture medium were transferred to the laboratory following sampling during a cold cycle. samples were then transferred into an incubator set at $37^{\circ} \mathrm{C}$ within the shortest time possible. Following 48 hours, the culture media were examined and developed colonies were counted using the eye. To calculate density of the counted colonies, first the volume of the sampling air was corrected and calculated considering temperature and air according to Equation 1, followed by correction and calculation of density using Equation 2 as cubic meter $\left(\mathrm{CFU} / \mathrm{m}^{3}\right)(20)$. To detect type of bacteria and type of fungi of the formed colonies, they were cultured in differential culture media. Following 48-72 hours, they were placed on a slide, whereby the type of microorganism was detected under microscope.

$\mathrm{P}_{2} \mathrm{~V}_{2} / \mathrm{T}_{2}=\mathrm{P}_{1} \mathrm{~V}_{1} / \mathrm{T}_{1}$

$P$ is the air pressure in terms of atmosphere, $V$ represents air volume per liter or cubic meter, $T$ denotes the temperature of the sampling air in terms of Kelvin.

Index 1 represents standard conditions, while index 2 shows conditions of the studied medium.

$\mathrm{CFU} / \mathrm{m}^{3}=1000 \mathrm{P} / \mathrm{TV}$

$P$ is the number of colonies developed in the plate, $T$ is sampling time, and $V$ shows the amount of sampled air in liters or cubic meters.

Next, data were introduced into Excel 2007 and SPSS 16 for analysis, where firstly, normality of fungal density and bacterial density variables were examined by KolmogorovSmirnov test. To investigate the means of bacterial and fungal density across different hospitals, the parametric test of analysis of variance was employed. Furthermore, to investigate means of bacterial and fungal density across different wards in various hospitals, considering normality of the two variables of fungal and bacterial density, the parametric test of analysis of variance was utilized.

Results

The results obtained from density of bio-aerosols in the hospitals with over 300 bed capacity in Kerman are summarized in Table 1.

According to the results shown in Table 1, Shahid Bahonar hospital had higher levels of bacterial and fungal density than Shafa and Afzalipour hospitals. The mean bacterial density in the operation room of Shafa hospital had the highest contamination load, while the intensive care unit (ICU) ward of this hospital had the lowest contamination 
Table 1. The mean of bacterial and fungal bio-aerosols based on colonies per cubic meter in the educational hospitals of Kerman city in 2014

\begin{tabular}{|c|c|c|c|c|c|c|c|c|c|}
\hline \multirow{2}{*}{ Hospital } & \multirow{2}{*}{ Ward } & \multicolumn{2}{|c|}{ Bacterial density } & \multicolumn{2}{|c|}{ Total mean } & \multicolumn{2}{|c|}{ Fungal density } & \multicolumn{2}{|c|}{ Total mean } \\
\hline & & Mean \pm SD & $P$ & Mean \pm SD & $P$ & Mean \pm SD & $\boldsymbol{P}$ & Mean \pm SD & $P$ \\
\hline \multirow[t]{5}{*}{ Afzali } & ICU general & $58.43 \pm 1.90$ & 0.051 & $72.38 \pm 3.91$ & $<0.001$ & $18.93 \pm 9.44$ & 0.015 & $17.20 \pm 8.65$ & 0.001 \\
\hline & Operation room & $98.65 \pm 3.87$ & & & & $8.16 \pm 2.77$ & & & \\
\hline & Infection ward & $93.10 \pm 5.51$ & & & & $19.51 \pm 7.55$ & & & \\
\hline & Emergency & $56.44 \pm 2.64$ & & & & $17.02 \pm 5.17$ & & & \\
\hline & Bronchoscopy & $45.94 \pm 1.77$ & & & & $23.24 \pm 1.03$ & & & \\
\hline \multirow[t]{5}{*}{ Bahonar } & Operation room & $127.72 \pm 4.91$ & 0.058 & $102.68 \pm 4.2$ & $<0.001$ & $24.91 \pm 1.11$ & 0.028 & $28.15 \pm 1.20$ & 0.001 \\
\hline & Emergency & $77.07 \pm 1.73$ & & & & $18.49 \pm 7.24$ & & & \\
\hline & Internal ward & $137.74 \pm 5.55$ & & & & $27.55 \pm 1.09$ & & & \\
\hline & ICU general & $75.77 \pm 1.81$ & & & & $38.45 \pm 1.45$ & & & \\
\hline & Oncology ward & $99.80 \pm 2.56$ & & & & $30.13 \pm 8.74$ & & & \\
\hline \multirow[t]{5}{*}{ Shafa } & Burn ward & $59.73 \pm 3.25$ & 0.002 & $74.27 \pm 6.07$ & $<0.001$ & $33.41 \pm 2.03$ & 0.053 & $23.93 \pm 1.4$ & 0.001 \\
\hline & Operation room & $182.42 \pm 5.34$ & & & & $20.69 \pm 1.40$ & & & \\
\hline & ICU general & $29.71 \pm 9.77$ & & & & $14.20 \pm 2.63$ & & & \\
\hline & $\mathrm{CCU}$ & $52.29 \pm 9.04$ & & & & $20.33 \pm 3.48$ & & & \\
\hline & ICU stroke & $58.89 \pm 2.70$ & & & & $29.22 \pm 8.13$ & & & \\
\hline
\end{tabular}

load. Similarly, comparison showed that in the operation room ward of Afzalipour hospital, the lowest fungal contamination load was observed, while in the ICU ward of Bahonar hospital, the largest fungal contamination was seen.

In spite of detection of the hazards of exposure to bioaerosols, no allowable limit has been recommended to date and the available values are suggestions. These suggestions have a wide range, probably due to the diversity of bio aerosols and relate to different potential pathogens. The guideline limit proposed in this study is 75 colonies per cubic meter, according to the suggestion of American Conference of Governmental Industrial Hygienists (ACGIH) (21). The studied hospitals were found to have higher density of bio-aerosol than that proposed limit. Statistical analysis implies normality of the 2 variables of fungal and bacterial density $(P=0.2)(P=0.3)$. The means of bacterial density $(P \leq 0.001)$ and fungal density $(P \leq 0.001)$ were not equal across the studied hospitals and statistically, a significant difference was observed between the means of bacterial and fungal density. The results indicated that only in Shafa hospital was there a difference in the various wards in terms of mean bacterial density $(P=0.002)$. Investigation of the mean of fungal density in Afzalipour and Bahonar hospitals also indicated that the mean fungal density was variable across the different wards $(P=0.028, P=0.015)$.

Figure 1 represents frequency of organisms (fungal) isolated from the culture samples collected from the air of the studied hospital.

The greatest and lowest percentages of fungi observed in the air of hospitals belonged to Aspergillus niger (32.9), and Rhodotorula and Parasiticus (0.4), respectively. The bacterial frequency of the culture samples of the air of the wards of the studied hospitals is provided in Figure 2.

Based on the results from Figure 2, the greatest bacterial frequency separated from the air samples of hospitals was staphylococci (96), and the lowest one belonged to strepts (0.2).

The operating rooms and other wards used air conditioning and natural ventilation respectively. Number of patients in

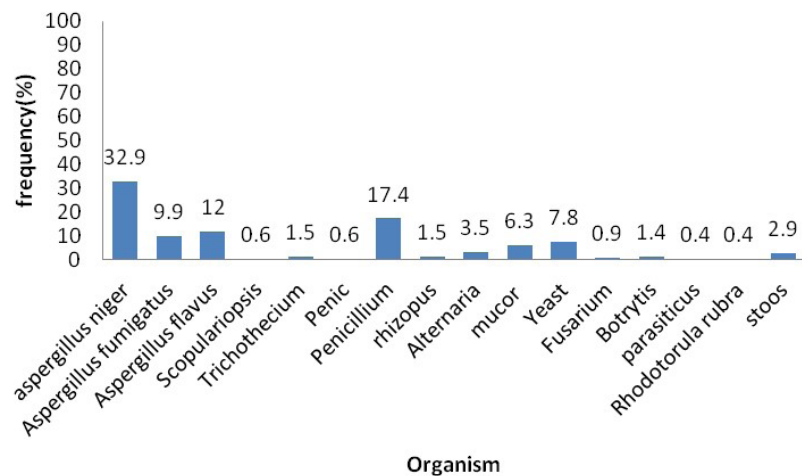

Figure 1. The frequency of organisms (fungal) isolated from the culture samples of the environmental air of different wards of the selected hospitals (in terms of percentage) in 2014

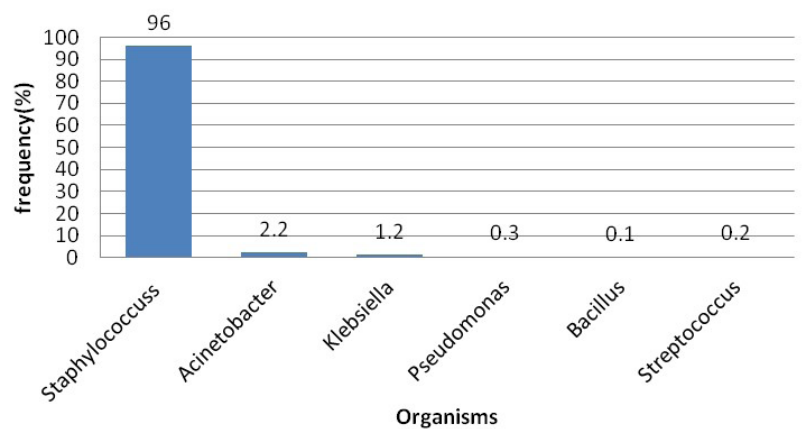

Figure 2. The frequency of organisms (bacterial) isolated from the culture samples of the environmental air of different wards of the selected hospitals (in terms of percentage) in 2014.

each ward was variable.

Discussion

Based on the results obtained from this study, the mean density of bio-aerosols in Shahid Bahonar hospital was 130.83 colonies $/ \mathrm{m}^{3}$, while in Shafa and Afzalipour hospitals it was 98.2 and 89.58 colonies $/ \mathrm{m}^{3}$, respectively. 
Contamination loads were detected in all selected wards, implying that the studied hospitals were contaminated. In the study by Mohammadian et al, on microbial contamination of the air of Imam Khomeini hospital and Shahid Zare hospital in Sari, microbial contamination was found across all of the wards of the mentioned hospital especially the general surgery ward (22). In their study in Jordan on educational hospitals in terms of microbial contamination, Qudesiat et al reported higher levels of contamination in all wards of educational hospital in comparison with private hospital (23). The mean bacterial $(P \leq 0.001)$ and fungal $(P \leq 0.001)$ densities in the studied hospitals were significantly different, thus air samples of the studied hospitals were not identical in terms of bacterial and fungal contamination. This can be attributed to type of service offered in each particular hospital.

Among the reasons for increased density of microorganisms in some hospitals are commuting and crowd inside the ward as well as the type of services and hospitalized patients in the hospital $(24,25)$. Bahonar hospital, is an old hospital that hosts patients with trauma (impact), the number of visitors is larger than other hospital, thus it is regarded as a busy place. In its own right, this factor can be a reason of the high level of bioaerosol density, compared with other hospitals. Okhuoya and Okaraedge reported on a study in Nigeria where the population of visitors and their activities were mentioned as factors contributing to contamination load with bioaerosols (26). Juhee et al concluded that hospital location and ventilation, and number of people had an effect on bio-aerosol concentration (27).

Arab et al demonstrated on a study on fungal spores of the air inside Kerman hospital. The report mentions that the level of fungal density in Bahonar hospital was greater than that in other hospitals due to types of patients, age of building, and the large number of visitors (28). The geographical position of a hospital is another important factor. Bahonar hospital is located in the city center and is thus affected by the quality of air surrounding the hospital. Environmental observations imply that in Bahonar hospital, a central and standard ventilation system was not used for ventilating the air inside the wards and that natural air-flow with no pretreatment was used for ventilation. Fang et al conducted a study in China in which consideration of different factors of bacterial density in the human accommodation as geographical and environmental conditions were applied (29). Hoseinzadeh et al stated high bio-aerosol density in 2 hospitals located in Hamedan: Shahid Beheshty and Bessat due to the high rate of visitors and their geographical location. These two hospitals are located in the suburb of the city and the quality of the air inside is affected by its open aspect and the surrounding air (1).

The most polluted ward in these three hospitals was the operation room of Shafa hospital, where the contamination level in the operation rooms selected from the three hospitals was larger than the guideline limit proposed by ACGIH. There are various factors involved in contamination of these wards including lack of suitable ventilation, traffic of personnel and students, lack of a proper disinfection system, not taking hygiene seriously, frequency of surgical operations, and insufficient opportunity for sterilization. Choobineh et al studied educational hospitals of Shiraz city and reported the mean density of bio-aerosols in operation rooms as high due to a defective ventilation system and the procedure of disinfection, congruent with our study (4). Osaro et al studied bio-aerosols of private and public educational hospitals of Benin city in Nigeria and reported that the level of density of bio-aerosol density in operation rooms was the lowest, while this density was at its maximum in the pediatric and gynecology ward. The reason for low-level contamination in the operation room was attributed to the following health standards, application of disinfection and air ventilation systems, and utilization of ultraviolet lamps (30). The lowest level of contamination in Shafa hospital was observed in the ICU ward, where accuracy in cleansing, disinfecting, controlling traffic, and application of equipment was high, with a ventilation system also installed in this ward. Kim et al studied 5 public hospitals in South Korea. They reported the lowest level of bio-aerosol contamination in the ICU ward due to use of a sterilized building, high level of ventilation, and control of the traffic of visitors (11).

In this research, 16 fungal and six bacterial species were identified. The diversity of fungal species is due to their greater adaptability and durability than bacterial bioaerosols across different wards of the hospitals. The most commonly observed fungi were Aspergillus niger and Penicillium. Furthermore, in the bacterial group, staphylococci and Acinetobacter were reported as the most common forms. Jaffal et al detected Staphylococcus, Bacilli, and Streptomyces from the bacterial group along with Alternaria, Aspergillus, Penicillium from the fungal groups, which are in accordance with results of this investigation (31). Osaro et al studied Benin hospital in Nigeria and detected gram-positive cocci as the most frequent microorganism in the air of the hospital (30). Pastuszka et al reported on a study on a hospital in Poland and mentioned higher density of bio-aerosol for bacteria species such as Micrococcus and Staphylococcus (32). The greatest frequency was determined between bacterial bio-aerosols across all of the hospitals belongs to Staphylococcus. Staphylococcus is not very toxic, but the bacteria are an important cause of infections in high-risk groups (33). Furthermore, they are absolutely resistant to dry and highly aseptic conditions. These characteristics facilitate their life in the environment, growth in food, and transmission-proneness (1). As Kerman province is located in the southeast of the run, lack of rainfall and high evaporation rate, it is present in the dry provinces of Iran. It is thus expected that its value is high.

Moreover, Panagopoulou et al reported on a study on air contamination of three hospitals in Greece. It was found that in terms of fungi, the greatest number of detected fungi was related to the Aspergillus genus (34). A study of Awosika et al revealed that the maximum of the study of fungal and bacteria concentrations were Aspergillus, Penicillium and Staphylococcus, respectively (35). Due to their ability for growth and proliferation in any place and development of thin and permeable spores into the depth of alveolus and growth at $37^{\circ} \mathrm{C}$, Aspergillus species are observed frequently (36). Numerous sources have been considered for displacement of Aspergillus spores in hospitals including insufficient filtration of the outside air (as the most evident factor), soil, vacuum cleaners, and 
sudden displacement of air when a door is opened (28).

\section{Conclusion}

As healthcare centers for patients, hospitals should not support bio-aerosol contaminated, Based on the obtained results and regarding the fact that bio-aerosol density was greater than the ACGIH proposed level in $73.3 \%$ of the wards selected in the studied hospitals, implementation of a comprehensive plan to combat this contamination is essential in educational hospitals of Kerman. However, as a hospital is a center for all diseases, many individuals in hospitals care carriers of a wide range of diseases, causing hospital infections in all people especially sensitive people (children and the elderly), and incurring huge economic losses to the health ministry. It seems that accurate investigation and determination of the levels of bio-aerosol, objective inspection and evaluation by experienced experts, and use of disinfecting compounds, control of the passage of people, application of UV lamps, and an efficient ventilation system corresponding to global standards can greatly help in the management and significant reduction of air contamination in hospitals. Therefore, it is suggested that by stipulating some regulations for this issue (bio-aerosols) in hospitals of the country, necessary measures regarding continuous monitoring, promotion of disinfection levels, and ventilation systems are taken more seriously. It is expected that by keeping track of the problems and use of the proposed solutions, that the authorities would be able to decrease contamination load (bio-aerosol) in hospitals and provide a safe environment for patients and employees.

\section{Acknowledgments}

This research was conducted at the Environmental Health Engineering Research Center and was sponsored by the Vice-Chancellor for Research and Technology of Kerman University of Medical Sciences. A note of appreciation is expressed here to the Vice-Chancellor and to all university staff who provided assistance to make this study possible.

\section{Ethical issues}

The authors certify that all data collected during the study period are presented in this manuscript, and no datum from this study has been or will be published separately.

\section{Competing interests}

The authors declare that they have no competing interests

\section{Authors' contributions}

All authors participated in the design of the study, performed the literature search and wrote the manuscript, data acquisition, analysis, and interpretation. All authors critically reviewed, refined, and approved the manuscript.

\section{References}

1. Hoseinzadeh E, Samarghandie MR, Ghiasian SA, Alikhani MY, Roshanaie G. Evaluation of bioaerosols in five educational hospitals wards air in Hamedan, during 2011-2012. Jundishapur J Microbiol 2013; 6(6): e10704. doi: 10.5812/jjm.10704.

2. Karwowska E, Miaśkiewicz-Pęska E, AndrzejewskaMorzuch D. Microbiological air contamination in premises of the primary health-care. Arch Enviro
Prot 2013; 39(4): 51-8. doi: 10.2478/aep-2013-0034.

3. Amanlo S, Farjah GH, Taghavi M, Kalarestagh H, Jahantigh H, Sabouri GH. Microbial contamination of operation rooms in Amir-al Mominin hospital of Zabol, Iran. Journal of North Khorasan University of Medical Sciences 2011; 3(3): 7-14. [In Persian].

4. Choobineh A, Rostami R, Tabatabaei SH. Assessment of bioaerosols types and concentration in ambient air of Shiraz University of Medical Sciences educational hospitals, 2008. Iran Occupational Health Journal 2009; 6 (2): 69-76. [In Persian].

5. Torkanloo H, Barati R, Naimi N. Microbial air monitoring in operating theatres in hospitals of North Khorasan University of medical sciences in Bojnurd in 2013. North Khorasan University of Medical Sciences 2014; 5(5): 1011-5. [In Persian].

6. Byrne D, Lynch W, Napier A, Davey P, Malek M, Cuschieri A. Wound infection rates: the importance of definition and post-discharge wound surveillance. J Hosp Infect 1994; 26(1): 37-43. doi: 10.1016/01956701(94)90077-9.

7. World Health Organization. Prevention of HospitalAcquired Infections. Geneva, Switzerland: WHO; 2002.

8. Olajubu AF, Osinupebi OA, Ismail L, Bosede O, DejiAgboola AM. Pattern of hospital associated infections in a teaching hospital in Nigeria. Asian Pac J Trop Dis 2012;2:S869-73. doi: 10.1016/S2222-1808(12)602825.

9. Omoigberale $\mathrm{M}$, Amengialue $\mathrm{O}$, Iyamu $\mathrm{M}$. Microbiological assessment of hospital indoor air quality in Ekpoma, Edo State, Nigeria. Global Res J Microbiol 2014; 4(1): 1-5.

10. Ekhaise FO, Isitor EE, Idehen $\mathrm{O}$, Emoghene AO. Airborne microflora in the atmosphere of an hospital environment of University of Benin Teaching Hospital (UBTH), Benin City, Nigeria. World J Agric Sci 2010; 6(2): 166-70.

11. Kim KY, Kim YS, Kim D. Distribution characteristics of airborne bacteria and fungi in the general hospitals of Korea. Ind Health 2010; 48(2): 236-43. doi: 10.2486/ indhealth.48.236.

12. Setlhare G, Malebo N, Shale K, Lues R. Identification of airborne microbiota in selected areas in a healthcare setting in South Africa. BMC Microbiol 2014; 14: 100. doi: 10.1186/1471-2180-14-100.

13. Harper TA, Bridgewater S, Brown L, Pow-Brown P, Stewart-Johnson A, Adesiyun AA. Bioaerosol sampling for airborne bacteria in a small animal veterinary teaching hospital. Infect Ecol Epidemiol 2013;3:20376. doi: 10.3402/iee.v3i0.20376

14. Bhatia L. Impact of bioaerosols on indoor air quality-a growing concern. Advances in Bioresearch 2011;2(2):120-3.

15. Gioffrè $\mathrm{A}$, Dragone $\mathrm{M}$, Ammoscato I, Iannò $\mathrm{A}$, Marramao A, Samele P, et al. The importance of the airborne microorganisms evaluation in the operating rooms: the biological risk for health care workers. G Ital Med Lav Ergon 2007; 29(3 Suppl): 743-5. [In Italian]. 
16. Malakootian M, Radhakrishna N, Mazandarany MP, Hossaini H. Bacterial-aerosol emission from wastewater treatment plant. Desalination and Water Treatment 2013; 51(22-24): 4478-88. doi: $10.1080 / 19443994.2013 .769668$.

17. Curtis L, Prevention of hospital-acquired infections: review of non-pharmacological interventions. J Hosp Infect 2008; 69(3): 204-19. doi: 10.1016/j. jhin.2008.03.018.

18. Sadeghi Hasanvand Z, Sekhavatjo M, Zakavat R. Assessment the bio-aerosols type and concentration in various wards of Valiasr hospital, Khorramshahr during 2011. Health and Environmental 2013; 6(2): 201-10. [In Persian].

19. Dehdashti A, Sahranavard N, Rostami R, Barkhordari A, Banayi Z. Survey of bioaerosols type and concentration in the ambient air of hospitals in Damghan, Iran. Journal of Occupational Medicine 2013: 4(3): 41-51. [In Persian].

20. Pathak AK. An extramural aero mycological investigation of dental college hospital associated environment. Int J Environ Sci 2012; 2(4): 1952-61.

21. Ghorbani Shahna F, Joneidi Jafari A, Yousefi Mashouf R, Mohseni M, Shirazi J. Type and concentration of bioaerosols in the operating room of educational hospitals of Hamadan University of Medical Sciences and effectiveness of ventilation systems, in year 2004. Journal of Hamadan University of Medical Sciences 2005; 2(13): 70-64. [In Persian]

22. Mohammadian M, Movahedi MA. Assessment of biological agents in the air of different wards in Imam Khomayni and Shahid Zare hospitals in Sari, 2007. Journal of North Khorasan University of Medical Sciences 2010; 2(2-3): 51-8. [In Persian]

23. Qudiesat K, Abu-Elteen K, Elkarmi A, Hamad M, Abussaud M. Assessment of airborne pathogens in healthcare settings. Afr J Microbiol Res 2009; 3(2): 66-76.

24. Lee LD, Berkheiser M, Jiang Y, Hackett B, Hachem RY, Chemaly RF, et al. Risk of bioaerosol contamination with aspergillus species before and after cleaning in rooms filtered with high-efficiency particulate air filters that housepatients with hematologic malignancy. Infect Control Hosp Epidemiol 2007; 28(9):1066-70.

25. Mirbahar AM, Memon BA. Bacteriological monitoring through air sampling in different locations of teaching/civil hospital Sukkur. J App Em 2005; 1(2): 13-5.

26. Okhuoya J, Okaraedge S. Microflora of road side air and leaf surfaces of selected vegetables. Nigerian J Pure Appl Am Sci 1992; 12: 42-8.

27. Juhee S, Jinyoung M, Kyunga J, Younghee Y. A study in airborn microorgnism in hopital in Seol, Korea. Korean J Environ Health 2007; 33(2): 104-14.

28. Arab N, Ghaemi F, Ghaemi F. Airborne fungi spores in different wards of hospitals affiliated to Kerman University of Medical Sciences. J Kerman Univ Med Sci 2006; 13(4): 246-55. [In Persian].

29. Fang Z, Gong C, Ouyang Z, Liu P, Sun L, Wang X. Characteristic and Concentration Distribution of Culturable Airborne Bacteria in Residential Environments in Beijing, China. Aerosol Air Qual Res 2014; 14(3): 943-53. doi: 10.4209/aaqr.2013.04.0109

30. Osaro EF, Ufuoma IO, Dorcas AO. Hospital indoor airborne microflora in private and government owned hospitals in Benin city, Nigeria. World J Med Sci 2008; 3(1): 19-23.

31. Jaffal A, Banat I, El Mogheth A, Nsanze H, Bener A, Ameen A. Residential indoor airborne microbial populations in the United Arab Emirates. Environ Int 1997; 23(4): 529-33. doi: 10.1016/S01604120(97)00055-X.

32. Pastuszka J, Marchwinska-Wyrwal E, Wlazlo A. Bacterial aerosol in Silesian hospitals: preliminary results. Pol J Environ Stud 2005; 14(6): 883-90.

33. Abdolahi AR, Mehrazma M. Concurrence of nosocomial infections with microorganisms spreading in the air of hospital wards. Med Lab J 2009; 3(2). [In Persian]

34. Panagopoulou P, Filioti J, Petrikkos G, Giakouppi P, Anatoliotaki M, Farmaki E, et al. Environmental surveillance of filamentous fungi in three tertiary care hospitals in Greece. J Hosp Infec 2002; 52(3): 185-91. doi: 10.1053/jhin.2002.1298.

35. Awosika SA, Olajubu FA, Amusa NA. Microbiological assessment of indoor air of a teaching hospital in Nigeria. Asian Pac J Trop Biomed 2012; 2(6): 465-8. doi: 10.1016/S2221-1691(12)60077-X

36. Barati B, Ghahri M, Sorouri R. Isolation and characterization of bacteria and fungi in ambient air of Qeshm Island. J Hormozgan Univ Med Sci 2009; 13(2): 101-8. [In Persian]. 